\title{
The Influence of Rough Rock Surface on the Heat Losses of Fire Gases in a Mine Drift
}

\author{
Rickard Hansen \\ The University of Queensland \\ Brisbane, QLD 4072, Australia \\ rickard.hansen@uq.edu.au
}

\begin{abstract}
The influence on the fire gases temperature with respect to the surface roughness in a mine drift is investigated. A number of correlations are investigated and compared with experimental results from full-scale fire experiments. During the analysis it is found that an expression by Nunner results in predicted average fire gas temperatures closest to the measured temperatures of the two experiments. The other correlations are found to significantly over predict the average fire gas temperature. During the occurrence of backlayering the correlation by Nunner is found to predict much higher temperatures. When subtracting the energy lost to backlayering, the resulting calculated temperature curve is found to fit the measured values very well. When calculating the average fire gas temperature, a key factor is determined with respect to the smoke spread in a mine drift as well as the risk of fire spread.
\end{abstract}

Keywords: Surface roughness, Heat loss, Fire gases, Mine drift, Longitudinal ventilation.

\section{Introduction}

The environment in a hard rock mine drift is distinguished by rough rock surfaces, where the surface roughness magnitude of the surrounding surfaces could be substantial. In the case of a fire in a mine drift the environment will affect the fire behaviour in numerous ways, such as the heat release rate of the fire and the heat losses of the streaming fire gases along the mine drift. An increasing surface roughness will increase the turbulence of the fire gases as well as the area of the surrounding rock surfaces which will result in an increasing heat transfer from the fire gases to the surrounding rock surfaces and a more rapidly decreasing fire gas temperature as opposed to a tunnel with smooth surfaces.

This paper focuses on and investigates the influence on the fire gases temperature with respect to the surface roughness in a mine drift with longitudinal ventilation and in the near vicinity of the fire. A number of correlations are investigated and the calculated values are compared with experimental values from earlier conducted full-scale fire experiments in a mine drift. The experimental data was obtained from full-scale experiments presented by Hansen and Ingason [1].

An earlier study show that better knowledge about smoke behaviour and fire spread is needed for underground hard rock mines [2]. A limited number of studies have been conducted on the heat exchange between rock and adjacent fluid in underground mines and tunnels. Wolski [3] conducted a study where the heat exchange between flowing air and tunnel walls was modelled. The convective heat transfer coefficient was calculated using an expression by Starfield and Dickson [4] who in turn had added a friction factor to an existing expression by Rohsenow and Choi [5] valid for smooth surfaces. Dziurzynski, Tracz and Trutwin [6] conducted simulations with a proposed mine fire model. Chang and Greuer [7] presented a paper that assumed circular airways with wood uniformly distributed over the entire airway walls. The surface roughness of the wall surfaces was not considered in the heat transfer calculations. McPherson [8] described a model where the overall heat transfer coefficient at the surface of the airway is assumed to vary mainly with the air velocity and the roughness of the airway surface. An empirical expression by Scott [9] was applied to calculate the overall heat transfer coefficient. Beard and Carvel [10] set forward the following expression for the average fire gas temperature over the entire cross-section at a given position along a tunnel with longitudinal ventilation:

$$
T_{a v g}(x, t)=T_{0}+\left[T_{a v g, x=0}(\tau)-T_{0}\right] \cdot e^{-\frac{h_{\text {total }} \cdot P \cdot x}{\dot{m}_{a} \cdot c_{p}}}
$$




$$
\begin{gathered}
\tau_{\text {transport }}=t-\left(\frac{x}{u}\right) \\
T_{\text {avg }, x=0}\left(\tau_{\text {transport }}\right)=T_{0}+\frac{2}{3} \frac{\dot{Q}(\tau)}{\dot{m}_{a} \cdot c_{p}}
\end{gathered}
$$

Where $T_{a v g}$ is the average gas temperature over the entire cross-section at a given position $(\mathrm{K}), T_{0}$ is the ambient temperature $(\mathrm{K}), \tau_{\text {transport }}$ is the transport time $(\mathrm{s}), h_{\text {total }}$ is the total heat transfer coefficient $\left(\mathrm{W} / \mathrm{m}^{2} \cdot \mathrm{K}\right), P$ is the perimeter of mine drift $(\mathrm{m}), x$ is the distance along the mine drift $(\mathrm{m}), \dot{m}_{a}$ is the mass flow in mine drift $(\mathrm{kg} / \mathrm{s}), c_{p}$ is the specific heat capacity of the fluid at constant pressure $(\mathrm{J} / \mathrm{kg} \cdot \mathrm{K}), u$ is the fluid velocity $(\mathrm{m} / \mathrm{s})$ and $\dot{Q}$ is the heat release rate $(\mathrm{kW})$.

The longitudinal ventilation velocity was assumed to be non-variant along the tunnel, a lumped heat transfer coefficient both for convective and radiative heat losses was assumed and the wall temperature was assumed to be equal to the ambient temperature. The roughness of the surfaces was not considered in the set of equations.

Hansen [11] conducted a study on the average fire gas temperature of multiple fires in a mine drift with longitudinal ventilation, but did not include the surface roughness factor as the applied fire experiments were conducted in a model-scale mine drift with smooth surfaces.

\section{Spread of fire gases and heat losses with respect to a rough mine drift surface}

Given the forced flow conditions and the extensive length of a mine drift, the transition to turbulent flow will take place close to the leading edge and will apply for the major part of the mine drift. Due to the enclosed nature, geometrical appearance and extensive length of the mine drift, the duct flow case would be the most appropriate case for the mine drift.

\subsection{The spread of fire gases in a mine drift}

The fire gases in a mine drift will ascend and spread along the ventilation direction. The smoke spread is largely determined by the occurring smoke stratification, which in turn is depending upon the air velocity in the mine drift, the dimensions of the mine drift, the heat release rate as well as the distance to the fire. With a low or no forced air velocity the smoke stratification is high in the vicinity of the fire while at the other end - at high air velocities - the smoke stratification is low downstream from the fire. With increasing mine drift height and increasing distance to the fire, the vertical temperature gradients will decrease and thus also the smoke stratification. An increase in the heat release rate will result in an increase in the vertical temperature gradients and an increase in the smoke stratification. Newman [12] presented a number of correlations for the temperature stratification in a duct fire using a Froude number correlation. Newman divided the duct into three different regions depending on the degree of stratification. The surface roughness will affect the stratification and smoke spread. An increasing surface roughness will lead to a decreasing stratification.

Downstream of the fire - providing that insignificant stratification prevails - the temperature gradient perpendicular to the flow direction will be near zero except for the region closest to the rock surface. Further upstream where the flow is not fully developed or where stratification prevails, the boundary layer will have a substantial influence on the heat transfer between the fluid and the rock surface. The influence of the boundary conditions on the heat transfer will have to be taken into account when examining the heat losses of the fire gases.

The solid boundary condition at a plane on the rock surface is $(y=0)$ - simplifying the gas phase details and applying a convective heat transfer coefficient:

$$
-\left.k \frac{\partial T}{\partial y}\right|_{y=0}=h_{c} \cdot\left(T_{g}-T_{w}\right)+\left.\dot{q}_{r a d}^{\prime \prime}\right|_{y=0}
$$


Where $k$ is the thermal conductivity $(\mathrm{kW} / \mathrm{m} \cdot \mathrm{K}), h_{c}$ is the convective heat transfer coefficient $\left(\mathrm{kW} / \mathrm{m}^{2} \cdot \mathrm{K}\right), T_{g}$ is the fire gas temperature $(\mathrm{K}), T_{w}$ is the wall temperature $(\mathrm{K})$ and $\dot{q}_{\text {rad }}^{\prime \prime}$ is the radiative heat flux $\left(\mathrm{kW} / \mathrm{m}^{2}\right)$.

For a full description of the governing equations, boundary conditions, assumptions and the radiative term of equation (4), see report by Hansen [13].

\subsection{Convective heat transfer coefficient}

Equation (4) assumes laminar flow. The flow in the mine drift will generally - due to the forced ventilation - be turbulent. For a rough surface the laminar viscous sublayer will be broken up, resulting in a dramatic decrease in the conductive resistance of the sublayer. The convective heat transfer coefficient for a rough surface can therefore be much larger than for a smooth surface for the same flow conditions. The convective heat transfer coefficient will vary with the surface roughness features. Applying the Nusselt number expression when calculating the convective heat transfer coefficient:

$$
N u_{L}=\frac{h_{c} \cdot L}{k}
$$

Where $N u$ is the Nusselt number and $L$ is the length of mine drift (m).

Turbulent duct flow for circular ducts has been extensively explored, which is not the case for rectangular ducts. Still the results for circular ducts can be applied for rectangular ducts as well with fairly accurate results, applying a hydraulic diameter [14] as the characteristic length.

A number of expressions for the Nusselt number - valid for fully developed turbulent duct flow, with a rough duct surface - are described below and were applied in the analysis. Martinelli [15] presented the following correlation:

$$
N u_{D_{h}}=\frac{\operatorname{Re}_{D_{h}} \cdot \operatorname{Pr} \cdot \sqrt{\frac{f}{2}}}{5 \cdot\left[\operatorname{Pr}+\ln (1+5 \cdot \operatorname{Pr})+0.5 \cdot \ln \left(\frac{\operatorname{Re}_{D_{h}} \cdot \sqrt{\frac{f}{2}}}{60}\right)\right]}
$$

Where $D_{h}$ is the hydraulic diameter of the mine drift (m), Re is the Reynolds number, Pr is the Prandtl number and $f$ is the Darcy friction factor.

A correlation valid for $\operatorname{Pr} \approx 0.7$ was given by Nunner [16]:

$$
N u_{D_{h}}=\frac{\operatorname{Re}_{D_{h}} \cdot \operatorname{Pr} \cdot\left(\frac{f}{2}\right)}{1+1.5 \cdot \operatorname{Re}_{D_{h}}^{-\frac{1}{8}} \cdot \operatorname{Pr}^{-\frac{1}{6}} \cdot\left[\operatorname{Pr} \cdot\left(\frac{f}{f_{\text {smooth }}}\right)-1\right]}
$$

Bhatti and Shah [14] presented the following correlation: 


$$
N u_{D_{h}}=\frac{\left(\operatorname{Re}_{D_{h}} \cdot \operatorname{Pr} \cdot\left(\frac{f}{2}\right)\right)}{1+\sqrt{\frac{f}{2}} \cdot\left(4.5 \cdot \operatorname{Re}_{\varepsilon_{\text {roughuess }}}^{0.2} \cdot \operatorname{Pr}^{0.5}-8.48\right)}
$$

Where $\varepsilon_{\text {roughness }}$ is the surface roughness amplitude (m).

A correlation by Bhatti and Shah [14], which is valid for $\operatorname{Re}>2300$ :

$$
N u_{D_{h}}=\frac{(f / 2) \cdot\left(\operatorname{Re}_{D_{h}}-1000\right) \cdot \operatorname{Pr}}{1+\sqrt{\frac{f}{2}} \cdot\left[\operatorname{Re}_{\varepsilon_{\text {roughness }}}^{0.5} \cdot\left(17.42-13.77 \cdot \operatorname{Pr}_{t}^{0.8}\right)-8.48\right]}
$$

Where $\operatorname{Pr}_{t}$ is the turbulent Prandtl number.

In the entry section of a duct or in a section with stratification, the vertical temperature gradient will not be constant, and the convective heat transfer coefficient will not be independent of the position in the direction of the flow. In this section the Nusselt number will be larger than for the fully developed case. In the case of a mine drift it could be assumed in most cases that the thermal conditions will develop with a fully developed velocity profile being present, as the position of for example the fan will be further upstream of the fire. This case is classified as having a thermal entry region [17] and the average Nusselt number for the entry region may be calculated applying the following correlation [18]:

$$
\frac{\overline{N u}_{D_{h}, \text { entry }}}{N u_{D_{h}}}=1+\frac{0.9756}{\left(\frac{x}{D_{h}}\right)^{0.760}}
$$

\section{Conducted full-scale experiments}

Two full-scale fire experiments on mining vehicles were conducted in an underground dolomite mine in Sweden. The full-scale fire experiments involved a loader and a drilling rig and were conducted in order to provide much needed data for future fire safety designs in underground mines. The longitudinal ventilation velocity and fire gas temperature was measured at certain heights at a measuring station, which was positioned $\sim 35 \mathrm{~m}$ downstream of the loader fire and $\sim 50 \mathrm{~m}$ downstream of the drilling rig fire. Approximate dimensions of the mine drift were $6 x 8$ meter $(\mathrm{HxW})$ and there were practically no differences in height between the fire and the measuring station. See paper by Hansen and Ingason [1] for further details on the experiments.

\subsection{Surface roughness measurements}

Given that the amplitude of the surface roughness will have a decisive impact on the viscous sublayer and therefore also on the heat transfer to the rock surface, the roughness structures are described by an average roughness amplitude in this paper.

The width of the mine drift - where the full scale fire experiments took place - was measured at a number of places in order to get a measure on the roughness amplitude. It was found that for the ten randomly chosen measuring points the roughness amplitude was approximately $0.1 \mathrm{~m}$. Roughness data on 54 mine drift sections were provided by LKAB Mining Corporation in order to investigate whether the calculated value above was a typical roughness value for a mine drift. The average roughness amplitude for the mine drift sections was calculated to approximately $0.11 \mathrm{~m}$, thus very close to the calculated value. 


\section{Three-dimensional analysis}

A model was set up in order to calculate the average fire gas temperature at the measuring station for the two full-scale fire experiments, applying the various listed correlations above. A quasi-steady process was applied in the model as a transient heat flux is faced and most equations for calculation of the surface temperature assume a constant heat flux. Microsoft Office Excel spreadsheet software was used during the calculation of the numerical model. A time increment of 1 second was applied in the calculations and the mine drifts of the experiments were divided into a number of segments in the axial direction with a width of $0.5 \mathrm{~m}$. For each time step and rock surface segment a number of parameters were calculated: Convective heat transfer coefficient; energy balance of control volume and fire gas temperature; rock surface temperature; temperature of interior rock nodes. For a full description of the of the calculation flow when calculating the convective heat transfer coefficient and increment in fire gas temperature, see report by Hansen [13].

The average fire gas temperature at the site of the fire was calculated using equation (3) and the heat release rates of the two experiments. The energy balance of a control volume of fire gases - where the boundary is the rock surface segment was expressed by:

$$
h_{c} \cdot\left(T_{g}-T_{w}\right) \cdot d A+\left.\dot{q}_{r a d}^{\prime \prime}\right|_{y=0} \cdot d A=\dot{m}_{a} \cdot c_{p} \cdot d T_{g}
$$

Where $A$ is the area $\left(\mathrm{m}^{2}\right)$ and $d T_{g}$ is the temperature difference of the fire gas $(\mathrm{K})$.

The temperature difference - $d T_{g}$ - was used when calculating the average gas temperature of the adjacent segment and time step. The solid boundary condition at a plane on the rock surface (equation (4)) was approximated applying a finitedifference approximation for the rock surface nodes (setting the energy conducted, convected and radiated into the node equal to the increase in the internal energy of the node), interior rock nodes and a one-dimensional cylindrical system.

Newman [12] presented a correlation between the mass concentration of any chemical compound and the local gas temperature rise. Studying the fire gas temperature readings at the measuring station during the drilling rig and the loader fire, it was found that the thermocouple $4.3 \mathrm{~m}$ above the ground displayed consistently higher temperatures while the thermocouple $3.1 \mathrm{~m}$ above the ground displayed more or less ambient temperatures throughout the two experiments. As the distance between the fire and the measuring station was within the region with distinct stratification, the height of the fire gas layer was assumed to be in between the two thermocouples - i.e. $3.7 \mathrm{~m}$ above ground - throughout the experiments.

\section{Results of experiments and three-dimensional analysis}

The resulting average fire gas temperature curves of the various correlations were calculated for the initial 20 minutes encompassing the time period to the maximum heat release rate of both experiments.

\subsection{Drilling rig fire}

When studying the average fire gas temperature curves of the drilling rig it can be seen that the correlation by Nunner equation (7) - matched the measured values very well during the initial 20 minutes. It was only during the very last phase as seen in figure 1 - that the correlation predicted much higher temperatures when comparing with the measured values. At this stage of the fire a backlayering started to occur. The other correlations were found to significantly over predict the average fire gas temperature at the measuring station. During the initial five minutes the calculated results follows the measured results nicely, but then gradually the difference between the results increase more and more. 


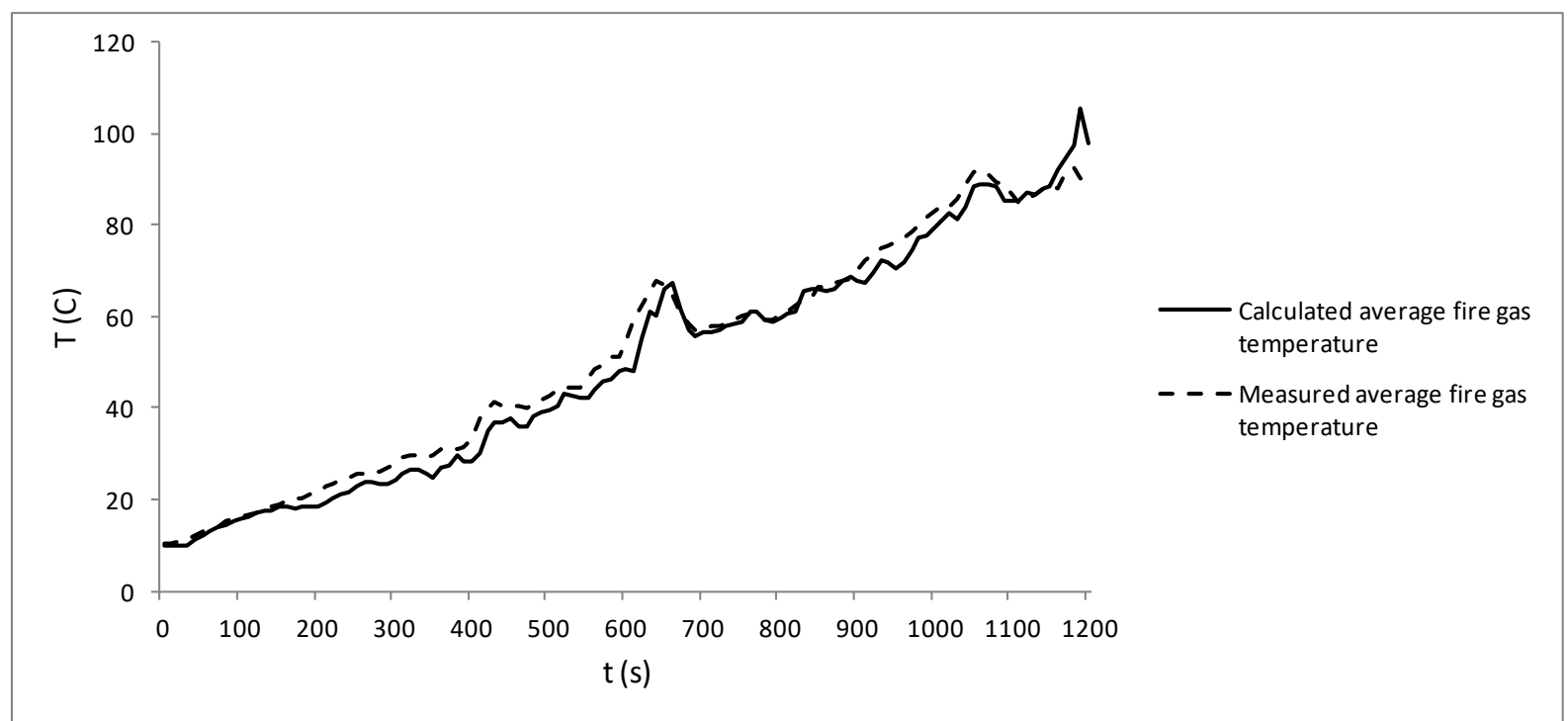

Fig. 1. The measured and calculated - using equation (7) - average fire gas temperature in the case of the drilling rig fire.

\subsection{Loader fire}

Same as for the drilling rig, the correlation by Nunner matched the measured values very well during the initial 10 minutes. During the ensuing 10 minutes - as seen in figure 2 - the correlation predicted much higher temperatures when comparing with the measured values. At this stage of the fire a backlayering started to occur, resulting in a maximum backlayering of $50 \mathrm{~m} \mathrm{[1].} \mathrm{The} \mathrm{other} \mathrm{correlations} \mathrm{were} \mathrm{found} \mathrm{to} \mathrm{significantly} \mathrm{over} \mathrm{predict} \mathrm{the} \mathrm{average} \mathrm{fire} \mathrm{gas} \mathrm{temperature} \mathrm{at}$ the measuring station.

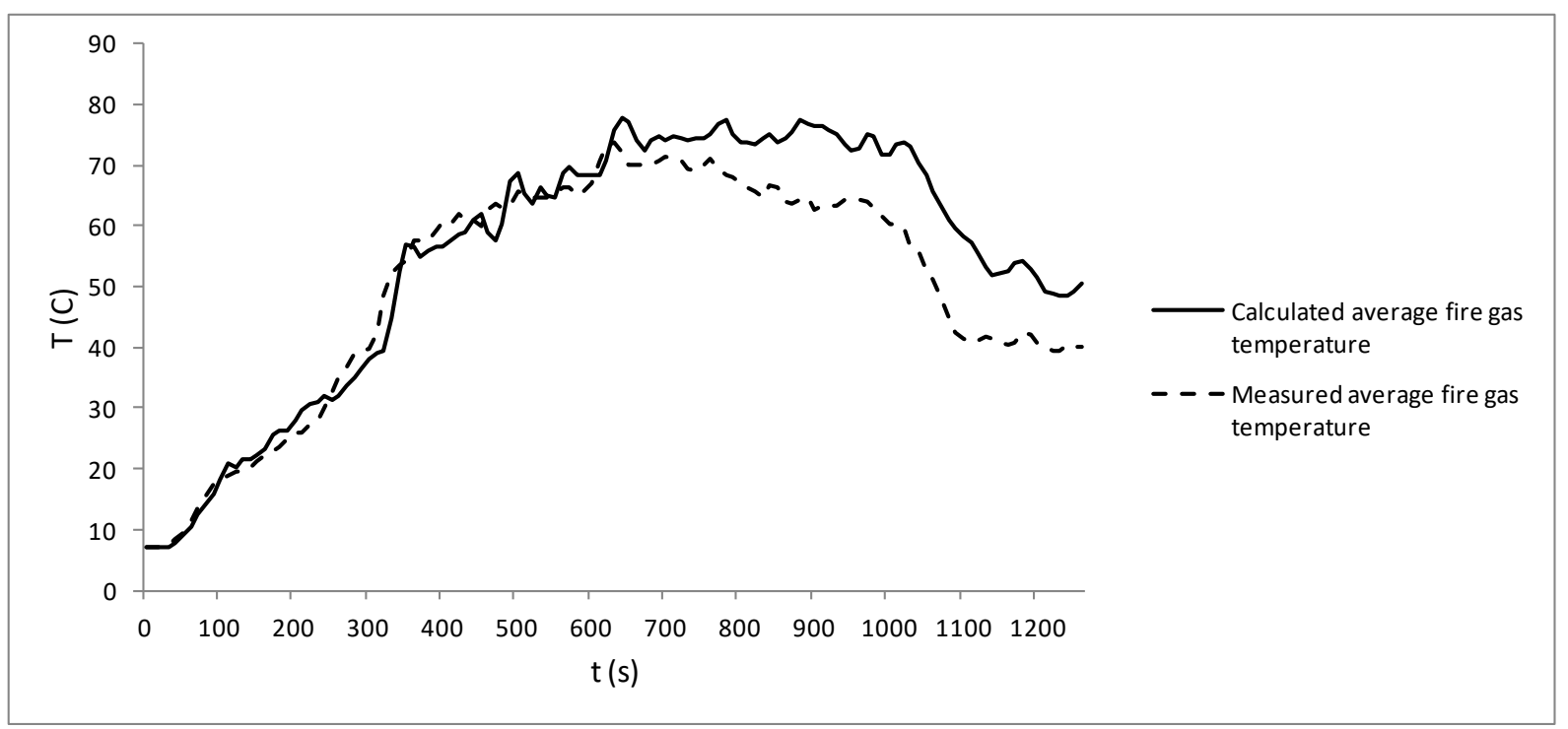

Fig. 2. The measured and calculated - using equation (7) - average fire gas temperature in the case of the loader fire.

\section{Discussion}

The correlation by Nunner clearly fitted the measured results from the two experiments best among the investigated correlations. This is in line with the finding of McPherson [19]. The correlation by Nunner matched the measured values very well during the initial 20 minutes of the drilling rig fire and the initial 10 minutes of the loader fire, a common denominator at these stages was the occurrence of the maximum heat release rate as well as backlayering. The standard deviation in the case of the drilling rig was $3.5^{\circ} \mathrm{C}$ and $2.8^{\circ} \mathrm{C}$ in the case of the loader, which are both low deviation values for a fire case. When backlayering occurred heat losses in the fire gases occurred upstream as well and the distance where 
losses occurred was therefore larger than the distance between the fire and the measuring station. The maximum backlayering in the case of the loader fire was $50 \mathrm{~m}$, if assuming that the backlayering increased linearly (no recordings of the backlayering as a function of the time were taken during the experiments) with time starting at $\mathrm{t}=600 \mathrm{~s}$ and subtracting the energy lost to backlayering at the various point of time from the heat release rate, the resulting temperature curve was found to fit the measured values very well. The standard deviation in this case was $3.1^{\circ} \mathrm{C}$ which is a low value for a fire case.

In the calculations of the analysis both the convective and the radiative heat transfer components were included. Calculations were performed where the radiative heat transfer component of the flame was set to zero in the case of the two experiments. It was found that the difference in the resulting average fire gas temperature was very small. Clearly, the convective heat transfer component dominated over the radiative heat transfer component. However, the radiative heat transfer component of the flame cannot be entirely ruled out when analysing the risk of ignition of an adjacent object as the view factor will increase if an object is in parallel to the flames instead of perpendicular.

Applying equation (7) and using the roughness amplitude of $0.06 \mathrm{~m}$ and $0.14 \mathrm{~m}$, it was found that the temperature difference was fairly small between the different roughness cases.

When studying the calculated rock surface temperatures of the two experiments it was found that the temperature increase at the site of the fire was more than 100 degrees after approximately 20 minutes. Further $20 \mathrm{~m}$ downstream of the fire the temperature increase was approximately 25 degrees. The temperature increase is considerable and will have to be taken into account during the calculations.

Calculations were performed where the height of the fire gas layer was lowered respectively raised by 1 meter. It was found that the 1 meter difference in fire gas layer height did not have a significant impact on the resulting temperature. Similar temperature differences were found when lowering the layer height by 1 meter.

Knowing the average fire gas temperature will be a key factor when analyzing the smoke behaviour and designing the egress safety of the area in question as well as the smoke control. Knowing the average fire gas temperature will also be a key factor when determining the risk of fire spread to adjacent items, setting up safety distances to prevent ignition of multiple objects etc. It is important to point out that the average fire gas temperatures measured and calculated in this paper were relatively low and would not have posed any significant risk with respect to fire spread.

As seen from the temperature results the rough rock surface in a mine drift will increase the heat losses of the fire gases compared with for example a tunnel with smooth surface. This in turn will decrease the risk of a flashover or a severe fire behaviour in a mine drift as the energy of the fire gases will not be sufficient. The open nature of a mine drift will decrease the risk even further, as fire gases will not be accumulated as in an enclosure.

\section{Conclusions}

It was found that an expression by Nunner resulted in predicted average fire gas temperatures closest to the corresponding temperatures of the two experiments. The other correlations were found to significantly over predict the average fire gas temperature. It was only during the later phases that the correlation by Nunner predicted much higher temperatures when comparing with the measured values. A common denominator at these stages was the occurrence of the maximum heat release rate as well as backlayering. When subtracting the energy lost to backlayering at the various point of time from the heat release rate, the resulting calculated temperature curve was found to fit the measured values very well.

A sensitivity analysis showed that the difference in the resulting average fire gas temperature is very small if the radiative heat transfer component of the flame was set to zero. This indicated that the convective heat transfer component dominated over the radiative heat transfer component of the flame at the position of the measuring station - approximately $35 \mathrm{~m}$ downstream of the loader fire and $50 \mathrm{~m}$ downstream of the drilling rig fire.

The rock surface temperature was found to increase at the site of the fire more than 100 degrees after approximately 20 minutes from the start of the fire. Further downstream of the fire the temperature increase was also found to be considerable and therefore the temperature increase will have to be taken into account during the calculations and cannot be neglected.

A fire in an underground mine will always pose a risk. But if knowing the average fire gas temperature, the smoke behaviour in an area could be analysed and appropriate measures could be taken with respect to the egress safety and the smoke control. This will increase the safety of the miners as well as the fire personnel.

\section{References}

[1] R. Hansen and H. Ingason, "Heat Release Rate Measurements of Burning Mining Vehicles in an Underground Mine," Fire Safety Journal, vol. 61, pp. 12-25, 2013. 
[2] R. Hansen, "Study of heat release rates of mining vehicles in underground hard rock mines," Ph.D. dissertation, Mälardalen University, Västerås, 2015.

[3] JK. Wolski, "Modeling of heat exchange between flowing air and tunnel walls," in Proceedings of the $7^{\text {th }}$ US Mine Ventilation Symposium, pp. 207-212, 1995.

[4] AM. Starfield and AJ. Dickson, "A study of heat transfer and moisture pick-up in mine airways," Journal of the South African Institute of Mining and Metallurgy, vol. 68, pp. 211-234, 1967.

[5] WM. Rohsenow and HY. Choi, Heat, mass and momentum transfer. Prentice-Hall Inc, 1963.

[6] W. Dziurzynski, J. Tracz and W. Trutwin, "Simulation of mine fires," $4^{\text {th }}$ International Mine Ventilation Congress, Brisbane, 1988.

[7] X. Chang and R. Greuer, "A mathematical model for mine fires," Proceedings of the $3^{\text {rd }}$ Mine Ventilation Symposium, pp. 453-462, 1987.

[8] MJ. McPherson, "The analysis and simulation of heat flow into underground airways," International Journal of Mining and Geological Engineering, vol. 4, pp. 165-196, 1986.

[9] DR. Scott, "The cooling of underground galleries," Transactions of the Institution of Mining Engineers, vol. 118, pp. 356-372, 1958.

[10] A. Beard and R. Carvel, The handbook of tunnel fire safety. London: Thomas Telford Ltd, 2005.

[11] R. Hansen, "Analysis of the average fire gas temperature in a mine drift with multiple fires," Journal of Sustainable Mining, vol. 17, pp. 226-238, 2018.

[12] JS. Newman, "Experimental Evaluation of Fire-Induced Stratification," Combustion and Flame, vol. 57, pp. 33-39, 1984.

[13] R. Hansen, "Heat Losses of Fire Gases in a Mine Drift with Rough Rock Surface and Forced Longitudinal Ventilation," Brisbane: The University of Queensland, 2017.

[14] MS. Bhatti and RK. Shah, "Turbulent and Transition Flow Convective Heat Transfer in Ducts," in Handbook of singlephase convective heat transfer, S. Kakaç, RK. Shah and W. Aung, Eds. Wiley-Interscience, 1987.

[15] RC. Martinelli, "Heat Transfer to Molten Metals," Trans. ASME, vol. 69, pp. 947-959, 1947.

[16] W. Nunner, "Wärmeübergang und Druckabfall in Rauhen Rohren," VDI-Forschungsheft 445, Ser. B, vol. 22, pp. 539, 1956.

[17] FP. Incropera, DP. Dewitt, TL. Bergman and AS. Lavine, Fundamentals of Heat and Mass Transfer. Hoboken: John Wiley \& Sons Inc, 2007.

[18] AF. Mills, "Experimental Investigation of Turbulent Heat Transfer in the Entrance Region of a Circular Conduit," $J$. Mech. Eng. Sci., vol. 4, pp.63-77, 1962.

[19] MJ. McPherson, Subsurface Ventilation and Environmental Engineering. Chapman \& Hall, 1993. 